\title{
QUEIXA ESCOLAR: UMA NOVA PROPOSTA DE AVALIAÇÃO
}

Thaís Emília de Campos ${ }^{1}$, Kelly Cristina dos Santos Silva ${ }^{2}$, Caroline Kraus Luvizotto ${ }^{3}$

${ }^{1}$ Aluna do Mestrado em Educação da UNESP - Marília. ${ }^{2}$ Aluna do Mestrado em Educação e Saúde na Infância e na Adolescência - UNIFESP. ${ }^{3}$ Docente do Mestrado em Educação da UNOESTE. E-mail: kellypsico@yahoo.com.br

\section{RESUMO}

Ao iniciarmos nossa atuação numa Secretaria de Educação nos Setores de Psicologia e Psicopedagogia notamos que as práticas enfatizavam avaliação e diagnósticos dos alunos para encaminhamentos médico. Para as escolas da rede, o trabalho da equipe multidisciplinar era uma ponte para os serviços de saúde, bem como representavam o acesso a profissionais que poderiam medicar. Neste sentido, este estudo teve como objetivo refletir, a partir da atuação dos membros das equipes escolares e professores, sobre os entraves nos processos de ensino aprendizagem, buscando, especificamente, descentralizar o foco no aluno e promover um olhar mais amplo para as queixas escolares, que possa contemplar as relações que se estabelecem nas instituições. 0 estudo baseou-se em uma pesquisa-ação e a análise seguiu a abordagem qualitativa de pesquisa. Por meio de nossas intervenções nas escolas percebemos o quanto os diagnósticos médicos são valorizadas pelos profissionais da educação e como estes são utilizados com justificativas para o fracasso escolar.

Palavras-chave: Processo de ensino e aprendizagem; Queixas escolares; Equipe multidisciplinar; Fracasso escolar; Diagnósticos médicos.

\section{INTRODUÇÃO}

Ao iniciar nossa trajetória em uma equipe multiprofissional na Secretaria Municipal de Educação de um município de pequeno porte do interior paulista, atuando na área de Psicologia e Psicopedagogia, observamos a existência de práticas de avaliação e diagnóstico de alunos no âmbito escolar.

O trabalho dos profissionais era centralizado em uma ficha de solicitação de acompanhamento, ou seja, os profissionais da equipe multidisciplinar disponibilizavam um modelo de ficha para as escolas, estas ao sentirem alguma necessidade, preenchiam a solicitação e enviavam para a equipe. Entretanto, o modelo de ficha de encaminhamento que vigorava na instituição era centralizado na criança, visava coletar a queixa da escola sobre o aluno.

As principais queixas realizadas pelas instituições de ensino orbitavam entre dificuldades para aprender e dificuldades para elaborar ou terminar as atividades propostas pelos professores. Quanto às queixas relacionadas aos comportamentos, observamos que as mais frequentes eram agitação, falta de atenção e concentração, envolvimento em brigas com colegas. Subjacentes a 
estas queixas, estavam os pedidos de elaboração de diagnósticos de alunos com suspeita dislexia e/ ou com transtorno de déficit de atenção e hiperatividade.

Para as escolas da rede, o trabalho da equipe multidisciplinar era uma ponte para os serviços de saúde, bem como representavam o acesso a profissionais que poderiam medicar. É importante destacar este desejo, porque nem sempre ele estava formalmente expresso no documento, mas estava muito presente nas falas de muitos profissionais que encaminhavam os alunos para a equipe. Este trâmite foi construído ao longo do tempo e teve, como destaca Patto (2008), participação ativa da psicologia, que por muito tempo atuou nas instituições escolares de forma clínica, cujo objetivo era tratar os problemas da criança sem problematizar as relações estabelecidas entre o aluno e seu processo de escolarização, que muitas vezes produzia o fracasso escolar.

Tal modo de pensar tornou-se hegemônico e cristalizado, pois tinha um amparo da ciência. Moysés (2001) traz importantes contribuições para o entendimento e aprofundamento desta temática. Ela busca compreender as origens da hegemonia do olhar clínico na escola que está fortemente relacionado à utilização dos testes de inteligência que teve como pilar os preceitos do Darwinismo, que foi amplamente redirecionado para o estudo do homem e das diferenças. Galton, primo de Darwin foi o responsável por este movimento, afirma que a espécie humana também era fruto de uma seleção, na qual apenas os mais aptos tinham melhores condições de vida. Nesta perspectiva o estimulo a casamentos entre os considerados biologicamente mais fortes tonou-se uma política. Entretanto, as pessoas com alguma doença, deficientes começaram a ser impedidas de terem filhos, através da realização de esterilizações.

Neste contexto, Catell, psicólogo que trabalhava com o estudo das diferenças individuais, começou a implementar testes para medir as funções de um individuo em comparação com uma média de pessoas, e Alfred Binet são os fundadores dos testes de inteligência. O ultimo, é o responsável pela publicação do primeiro teste, em 1905. Este foi elaborado a partir da observação de suas duas filhas e se preocupava em compreender porque algumas crianças apresentavam dificuldades na escola, pensava que isto ocorria porque ela não tinham desenvolvido sua inteligência da forma que era esperado, e assim, precisavam de um curso apropriado, denominado “ortopedia mental” (MOYSÉS, 2001).

A autora coloca ainda, que o teste criado por Binet permitia calcular a idade mental da criança, e desta forma predizer qual seria a ortopedia mais adequada. E pontuava que a inteligência não era considerada algo estático, ela poderia ser aumentada e pontuava o que o 
ambiente também fazia parte deste contexto. No entanto, enfatiza a expressão da inteligência em uma forma linear. Binet morre em 1911, e seus sucessores ingleses e franceses ficam restritos as ideias de Galton. "É importante ressaltar que, para Galton, assim como para a Psicologia nascente, o termo "diferenças individuais" não se refere à desejável pluralidade entre os homens, mas a diferenças decorrentes de indesejável miscigenação/degradação genética." (MOYSÉS, 2001, p.101).

Assim como o sucesso, observamos que a instituição escolar não se colocava como parte integrante do processo de fabricação de alunos que não aprendem na escola. Patto (2008), Collares e Moysés (1997) desenvolveram trabalhos referentes a produção do fracasso escolar e a circulação de diagnósticos clínicos na escola, respectivamente, tais trabalhos nortearam nossa análise e atuação.

Neste sentido, este estudo teve como objetivo refletir, a partir da atuação dos membros das equipes escolares e professores, sobre os entraves nos processos de ensino aprendizagem, buscando, especificamente, descentralizar o foco no aluno e promover um olhar mais amplo para as queixas escolares, que possa contemplar as relações que se estabelecem nas instituições.

\section{MÉTODO}

Este estudo teve como base a pesquisa-ação e seguiu a abordagem qualitativa de pesquisa científica. Após a análise das fichas de encaminhamento já enviadas para a equipe multidisciplinar, elaboramos um grupo de estudos para a implantação de um novo olhar para as queixas escolares.

As discussões sobre as fichas antigas e os debates suscitados pelo grupo de estudo contribuíram e embasaram a reformulação da ficha de encaminhamento, já que a anterior focava o aluno e sua família sem considerar outros aspectos que envolvem a aprendizagem: metodologia adequada ao estilo de aprendizado do aluno, relação professor $x$ aluno, como o aluno é posicionado e como ele se posiciona nos "campos sociais".

Ao elaborarmos uma nova ficha de encaminhamento, buscamos ampliar o campo de atuação e propiciar nas unidades escolares um espaço para discussões referentes à instituição escolar. A nova ficha continha apenas dois itens solicitante e a solicitação. Essa ficha poderia ser preenchida por qualquer funcionário da unidade escolar. Essa nova via de comunicação tornou possível a reflexão acerca das práticas pedagógicas e relações de poder nas escolas. Assim, seria possível ao professor ou a equipe gestora, queixar-se de algum problema vivenciado na escola. Buscamos enfatizar que as relações que se estabelecem na escola são fundamentais para 
aprendizagem dos alunos e que elas podem contribuir para o surgimento de entraves no processo de aprendizagem dos alunos.

A mudança de foco em relação aos encaminhamentos teve como ponto central a problematização dos pedidos de diagnósticos dos alunos. Os alunos deixaram de ser pensados como crianças que podem ter algum problema de comportamento ou alguma dificuldade para aprender. Os problemas que antes eram provenientes dos alunos passaram a ser da escola e da equipe multidisciplinar, ambas em conjunto deveriam criar estratégias e possibilidades para o enfrentamento dos problemas e a criação de estratégias para a superação das dificuldades.

Após a reformulação da ficha, entregamo-las e explicamos para as equipes gestoras de todas as Unidades Escolares (U.E.) a concepção que pautaríamos nosso trabalho. Realizamos vários encontros com as equipes escolares a fim de discutir a nova concepção do trabalho e a importância da parceira entre as escolas e a equipe multidisciplinar.

A etapa seguinte do trabalho constitui-se do manejo das queixas e construção de alternativas para o atendimento das solicitações e as discussões entre a equipe sobre a organização do trabalho, assim como do estudo e promoção de encontros para discutir a nova proposta de trabalho da equipe nas escolas.

\section{RESULTADOS}

Verificamos que tal mudança de perspectiva gerou uma serie de efeitos desde a construção de um novo pensar e agir até resistências ao trabalho, como criação de empecilhos para a participação em reuniões com professores e equipes.

As diferentes formas de reação observadas após a implementação das fichas podem ser interpretadas a partir da disponibilidade da equipe em pensar sobre suas próprias ações bem como de ouvir, ou seja, de estar disponível para efetivar mudanças, mesmo que elas sejam maiores e mais difíceis.

Por outro lado, muitas equipes, apesar do trabalho contínuo, permaneceram vinculadas ao modelo anterior. As fichas encaminhadas ao setor, ainda eram centralizadas no aluno, continham informações básicas referentes à idade, série, e questões relacionadas a problemas observados na sala de aula e alguns casos, as fichas continham, ainda, informações sobre a família da criança e excluíam quaisquer tipo de informações sobre a vida escolar da criança, por exemplo, como se relaciona com o professor, com os colegas, o nível de desenvolvimento, os avanços na aprendizagem, quais dificuldades tornavam-se mais persistes, ou até mesmo questões sobre 
alguma intervenção realizada pela escola. As orientações sobre estas especificidades foram, na grande maioria dos encaminhamentos, desconsideradas pelos professores ou membros da equipe escolar.

\section{DISCUSSÃO}

Olhar que predomina sobre esta problemática está desconectado aos estudos da década de 90 revelavam uma grande preocupação quanto ao encaminhamento de aluno para as classes especiais realizados por psicólogos, como afirma Souza (1997) ao explicitar que muitos psicólogos desconhecem os efeitos produzidos nos alunos após as avaliações e a falta de conhecimentos relativos à instituição educacional e a vida escolar da criança, pautando-se apenas em queixas individuais, "nega-se, com esses procedimentos, qualquer influência que a escola possa ter sobre o rendimento e o comportamento escolar da criança."(p.27)

Patto (2008), Collares e Moyses (1997) investigam a produção do fracasso escolar e a incessante busca das instituições escolares por diagnósticos clínicos a fim de justificar o fracasso de seus alunos.

Patto (2008) apresenta uma extensa pesquisa realizada numa escola de um bairro pobre do município de São Paulo. Neste estudo, foram realizadas observações nos diversos espaços da escola, assim como entrevistas com a equipe gestora, com os professores, análise dos relatórios psicológicos solicitados pela escola, além de um profundo encontro com quatro crianças e suas famílias a fim de compreender o sentido da escola, das avaliações realizadas por psicólogos clínicos. O estudo abarcou também o confronto entre a criança real com aquela descrita nos relatórios psicológicos, realizados sem a contextualização da vivência escolar da criança, dos fatores históricos e sociais entrelaçados ao cotidiano da escola, corroborando com a produção de crianças e famílias fracassadas.

A crítica em relação à utilização de avaliações psicológicas, sem quaisquer considerações sobre a realidade concreta em que a criança vive e também sobre o contexto em que os testes de inteligência foram criados e utilizados. As experiências colocadas por Machado, Souza e Sayão (1997) sobre as avaliações e diagnósticos e suas relações com o encaminhamento de crianças para as classes especiais soam como um alerta para a necessidade de mudança nos serviços oferecidos pela rede ensino, cujo principal objetivo é fortalecer a escola e seus profissionais para que possam garantir a aprendizagem de todos os alunos. 
Collares e Moysés (1997b), na mesma perspectiva de Patto, problematizaram a circulação de diagnósticos clínicos na escola. O estudo preocupava-se em compreender o fracasso escolar sob o ponto de vista dos professores e profissionais da saúde. As falas majoritariamente associavam o fracasso escolar a explicações relativas a problemas familiares, aos locais onde as crianças residiam, em questões nutricionais ou psicológicas. Problemas de saúde também eram respostas frequentes para justificar o fracasso escolar, enfatizando que a criança que não aprende na escola tem algo de errado e precisa ser tratada. Ao serem questionados por esta correlação, todos os entrevistados afirmaram que jamais haviam estudado o assunto e que aprenderam com prática. Saberes embasados no senso comum são disseminados nas escolas e produzem efeitos nas crianças, fazendo-as acreditar que são incapazes de aprender e efeitos na prática escolar, ocorrendo a expropriação do professor. "Qualquer um é competente para solucionar o problema, menos o professor, na verdade o único profissional com condições reais de transformar sua própria prática pedagógica, em busca do sucesso escolar." (COLLARES; MOYSÉS, 1997b, p.156).

As concepções encontradas por estas autoras são muito semelhantes as questões que surgiam nos encaminhamentos. As queixas relacionadas à saúde dos alunos, que na década de 1990 estavam relacionadas a problemas nutricionais ou psicológicos. Nos anos 2000, como o avanço dos estudos do cérebro e da farmacologia, começaram a receber outros nomes, dentre eles dislexia e transtorno de déficit de atenção e hiperatividade (TDAH).

Sobre esta perspectiva Moysés e Collares (2010a) ao trazer o panorama histórico do surgimento tanto da dislexia quanto do TDAH, revelam o olhar individualizante em que a questão é tratada, a maneira preconizada é medicalização. Ao enfrentar tal problemática, as autoras destacam que ao biologizar as questões sociais, a explicação para a não aprendizagem escolar é direcionada à criança, à criança que está doente (MOYSÉS; COLLARES, 2010b, p. 197).

O entendimento da nova ficha, para algumas equipes esteve baseada nestas concepções estudadas tanto por Collares e Moysés (1997), Moysés (2001) e Patto (2008), cuja cristalização do olhar está vinculada a presença da medicina na escola, a partir de um olhar voltado para o indivíduo, para suas capacidades e dificuldades individuais. E nesta perspectiva, Machado (2008) aponta a importância de olhos atentos aos processos de culpabilização e individualização, na busca por "soluções e alívios imediatos individuais (atendimentos, remédios, lexotans, ritalinas, florais, nutricionistas, psicólogos, especialistas...) para adoecimentos que se estabelecem socialmente..." (p.5) 
Os adoecimentos que se estabelecem socialmente dizem respeito, a um processo chamado por Moysés (2001) de medicalização da educação, ou seja, questões relacionadas a aspectos educacionais, sociais, econômicos, culturais, políticos são compreendidos como um problema que deve ser tratado individualmente, por agentes médicos e outros agentes da saúde, que irão propor uma solução para tal problema.

O olhar medicalizante tem um viés patologizante, ou seja, problemas das mais diferentes ordens são entendidos como uma doença e por isso, precisam ser tratados a partir do olhar médico. Tal concepção é hegemônica, o que nos coloca diante de diversas resistências, algumas traduzidas em falta de tempo para organizar grupos de discussões.

A elaboração de diagnósticos via psicólogos e psicopedagogos pode ser compreendida como uma forma de trabalho que não implica uns dos principais atores do processo de escolarização: professores e equipes escolares. Já a nova proposta traz em seu bojo algumas rupturas que desestabilizam, que podem causar desconfortos, que geram discussões e debates. A emergência da circulação das vozes daqueles que trabalham com os alunos produz muitas possibilidades de enfrentamento dos problemas, mas ao mesmo tempo, causa medo e desconforto.

\section{CONCLUSÃO}

A elaboração desta proposta nos fez compreender o modo como os diagnósticos médicos são valorizadas pelos profissionais da educação e como estes são utilizados com justificativas para o fracasso escolar. Aspectos sociais, históricos e econômicos são totalmente excluídos desta composição e impedidos de serem discutidos e problematizados, sobretudo porque as explicações fundamentadas em disfunções orgânicas são consideradas adequadas para os entraves nos processos de escolarização de crianças.

Observamos que a proposição de um novo olhar poder gerar uma série de desconfortos e desestabilizações, nas quais as discussões são de várias maneiras silenciadas, buscando um diagnóstico clínico a um fenômeno que é amplo e complexo.

Portanto, é fundamental que possamos compreender todas as facetas que compõe a problemática das queixas escolares para que possamos criar estratégias e soluções para os problemas que surgem no ambiente escolar e a necessidade que eles sejam solucionados neste espaço. É imprescindível a presença do diálogo e a circulação de diferentes propostas de trabalho, a troca de experiências, a criação novos modos de olhar para as crianças que não aprendem ou 
não apresentam o comportamento que a escola elege como adequado ou esperado a fim de superar o paradigma medicalizante.

\section{REFERÊNCIAS}

COLLARES, C. A. L.; MOYSÉS, M. A. A. Respeitar ou submeter: a avaliação de inteligência em crianças em idade escolar. In: MACHADO, A. M. et al. Educação Especial em Debate. São Paulo: Casa do Psicólogo, Conselho Regional de Psicologia, 1997a.

.O Profissional da Saúde e o Fracasso Escolar: Compassos e Descompassos. In: MACHADO, A. M. et al. Educação Especial em Debate. São Paulo: Casa do Psicólogo, Conselho Regional de Psicologia, 1997b.

MACHADO, A. M.; SOUZA, M. P. R.; SAYÃO, Y. As classes especiais e uma proposta de avaliação psicológica. In: MACHADO, A. M. et al. Educação Especial em Debate. São Paulo: Casa do Psicólogo, Conselho Regional de Psicologia, 1997.

MACHADO, A. M. A produção de Desigualdades nas Práticas de Orientação. 2008

Disponível em:

<http://www2.fe.usp.br/ cpedh/Desigualdade\%20e\%20Educ\%20Adriana\%20Marc.pdf >.Acesso em setembro de 2009.

MOYSÉS, Maria Aparecida A. A institucionalização do invisível: Crianças que não aprendem na escola. Campinas, SP: Mercado de Letras, 2001.

MOYSÉS, M. A. A.; COLLARES, C. A.L. Dislexia e TDAH: uma análise a partir da ciência médica. In: Conselho Regional de Psicologia, Grupo Interinstitucional Queixa Escolar (Orgs.). Medicalização de Crianças e Adolescentes - conflitos silenciados pela redução de questões sociais a doenças de indivíduos. São Paulo: Casa do Psicólogo, 2010a.

.Preconceitos no cotidiano escolar: a medicalização do processo ensino-aprendizagem. In: Conselho Regional de Psicologia, Grupo Interinstitucional Queixa Escolar (Orgs.). Medicalização de Crianças e Adolescentes - conflitos silenciados pela redução de questões sociais a doenças de indivíduos. São Paulo: Casa do Psicólogo, 2010b.

PATTO, M. H. S. A produção do fracasso escolar: histórias de submissão e rebeldia. São Paulo: Casa do Psicólogo, 2008.

SOUZA, M. P. R. A queixa escolar e o predomínio de uma visão de mundo. In: MACHADO, A. M. ; SOUZA, M. P. R. (Orgs.) Psicologia Escolar: em busca de novos rumos. SP: Casa do Psicólogo. 1997. 